\title{
THERMOECONOMIC ANALYSIS OF A WATER TO WATER HEAT PUMP UNDER DIFFERENT CONDENSER AND EVAPORATOR CONDITIONS
}

\author{
B. Aksu ${ }^{1, *}$, C. Uysal ${ }^{2}$, H. Kurt ${ }^{3}$
}

\begin{abstract}
A thermoeconomic analysis of a water to water heat pump are performed under different condenser and evaporator conditions. Experiments are realized for different volumetric inlet temperatures of 14.4, 17 and 19 ${ }^{\circ} \mathrm{C}$ and different volumetric flow rates of 50,100, $150 \mathrm{lt} / \mathrm{h}$ for condenser cooling water. Same inlet temperatures with condenser cooling water are used for evaporator water inlet, while constant volumetric flow rate of $100 \mathrm{lt} / \mathrm{h}$ is used for each case. Modified Productive Structure Analysis (MOPSA) is used for thermoeconomic analysis. It is found that increases in inlet temperature and in volumetric flow rate cause to decrease in both the unit cost of heat delivered $\left(C_{H}\right)$ and the unit cost of entropy generation $\left(C_{S}\right)$. As a result, in the case of $T_{i n}=14.4{ }^{\circ} \mathrm{C}$ and $\dot{\forall}$ $=50 \mathrm{lt} / \mathrm{h}, C_{H}$ and $C_{S}$ values are obtained to be $0.0489 \$ / \mathrm{kWh}$ and $0.0221 \$ / \mathrm{kWh}$, respectively, while $C_{H}$ and $C_{S}$ values are obtained to be $0.0385 \$ / \mathrm{kWh}$ and $0.0175 \$ / \mathrm{kWh}$ for $T_{i n}=19^{\circ} \mathrm{C}$ and $\dot{\forall}=150 \mathrm{lt} / \mathrm{h}$, respectively.
\end{abstract}

\section{Keywords: Water to Water Heat Pump, Condenser Cooling Water, Thermoeconomic Analysis, MOPSA}

\section{INTRODUCTION}

Growing energy demand, limited life time and reservoirs of fossil fuels and environmental effects caused by fossil fuel usage such as greenhouse effect and global warming cause to pay a more attention for alternative energy sources. In this sense, heat pump systems can be considered one of these energy sources because of that they provide cooling or heating by using non-fossil based energy sources. Heat pump systems transfer the energy from lower temperature source to higher temperature source. Different energy sources such as air, water and ground can be used by heat pump systems. To be able to provide the energy transfer from lower temperature source to higher one, heat pump systems consume electricity. Although the performance improvement studies in the manner of thermodynamics are important, the studies for economically assessment of this kind system are also important to be able to evaluate the unit cost of products.

Thermoeconomic analysis that combines thermodynamical and economic analysis is an effective tool to evaluate thermal systems. Thermoeconomic analysis provides an information for designers or engineers about the effect of some modifications or malfunctions and dysfunctions on the unit cost of system products. In this sense, several studies about thermoeconomic analysis of heat pump systems have been performed on.

Waheed et al. [1] have performed a study to reduce heat pump size and heat loss developed advanced vapor recompression heat pump models. They compared the thermoeconomic and environmental performance of the developed models with the traditional distillation process. As a result, the developed models provided significant energy savings. The total annual costs for the models were 92259 US\$, 92835 US\$, 95454 US $\$$, and cost savings were $33.6 \%, 29.7 \%$ and $24.4 \%$, respectively. Qureshi and Zubair [2] have investigated the thermoeconomic factors for the inventory of the heat exchanger at finite thermal capacities of irreversible refrigerants and heat pumps. As a result, the use of mathematical expressions would be better for determining the effect of the internal dissipation. Kodal et al. [3-4] have conducted performance analyzes using finite time thermodynamic based on a thermoeconomic objective function for irreversible refrigerators and heat pumps. They analytically derived optimum design parameters for the maximum conditions of the objective functions for refrigerators and heat pumps and have discussed the effects of internal irreversibility, economic parameters and external temperatures on global and optimal performance. Teyber et al. [5] have offered an optimization to minimize the permanent magnet and cooling cost in magnetic heat pumps. As a result, a constant temperature This paper was recommended for publication in revised form by Regional Editor Ozgen Acikgoz

${ }^{1}$ Gas and Gas Installation Program, TOBB Vocational School of Technical Sciences, Karabuk Uni., 78050, Karabuk, TURKEY

${ }^{2}$ Automotive Technologies Program, TOBB Vocational School of Technical Sciences, Karabuk Uni., 78050, Karabuk, TURKEY

${ }^{3}$ Mechanical Engineering Department, Faculty of Engineering \& Architecture, Necmettin Erbakan Uni., 42140, Konya, TURKEY

Orcid ld: 0000-0002-3976-8768, 0000-0002-7986-1684, 0000-0002-3409-9534

${ }^{*} E$-mail address: baksu@karabuk.edu.tr

Manuscript Received 19 December 2017, Accepted 14 March 2018 
range of $15 \mathrm{~K}$ and an optimal magnet configuration for $4.2 \mathrm{~kg}$ of gadolinium, using $16.3 \mathrm{~kg}$ of permanent magnet material, they obtained cooling power of $3.3 \mathrm{~kW}$ with a second law efficiency of 0.33 . Esfahani et al. [6] have developed a thermoeconomic model of an existing system which has low and high pressure compressors. The thermoeconomic model has been used to assess the unit cost of the fresh water and cooling to evaluate the flexibility of the system for fuel allocation from different electricity and heat energy sources. The results showed that the system with two compressors had high flexibility to allocate the different energy sources when the availability of the sources was limited for a given value of fresh water and cooling production.Verda et al. [7] have conducted thermoeconomic analysis for district heating networks operating at low temperatures. The analyzes were made on simple samples in order to provide a quantitative evaluation of various cost terms according to user / producer conditions, topology and properties.

Arat and Arslan [8] have investigated geothermal heat pump supported district heating system exergetically and economically by using NPL and LLC method. The results have showed that 13776 houses would be heated with this system and it could be an attractive investment for the region. Erbay and Hepbasli [9] have investigated the ground source heat pump drying system in terms of exergetic and advanced exergoeconomics. Results showed that total costs could be decrease from $4.008 \$ / \mathrm{h}$ to $2.569 \$ / \mathrm{h}$. For this, the improvements had to be made at drying tube and condenser. Sayyadi and Nejatolahi [10] have compared and discussed the results of optimizing by the ways of thermodynamic, thermoeconomic, and both thermodynamic both thermoeconomic according to the total revenue requirement model (TTR) of the cooling tower supported with ground source heat pump. Further, the sensitivity of optimized systems to the interest rate, the annual number of operating hours in cooling mode, the electricity price, and the water price are studied in detail. Erbay and Hepbasli [11] have found that the total cost was $1.347 \$ / \mathrm{h}$ and the exergoeconomic factor was 0.029 , by performing an exergoeconomic analysis of the ground source heat pump food dryer. Mastrullo and Renno [12] have investigated a model of heat pump whose evaporator operates as a photovoltaic collector in the terms of thermoeconomic and have compared the conventional heat pump with the photovoltaic heat pump thermoeconomically in the same operating conditions. Akbulut et al. [13] have experimentally and theoretically investigated exergoeconomic and exergoenvironmental analyses of wall cooling systems fed by a vertical type of ground source heat pump integrated wall cooling system for cooling mode. The results showed that the energy and exergy efficient of the whole system were $74.85 \%$ and $29.90 \%$, respectively. The external environmental effects of the whole system were found as $42.6 \%$ and the exergoeconomic factor as $77.68 \%$. Qin and Hao [14] have showed that the coefficient of performance of the sewage source heat-pump system approximates to 4.0. They have determined that the cost of the system is around $16.77 ¥ / \mathrm{m}^{2}$ and the annual cost of saving is around $444000 ¥$. When they examined the thermoeconomic cost of the system, they obtained an average value of 7.8 W/W. Erbay and Hepbasli [15] have compared the performance of the pilot scale air source heat pump food dryer with the traditional and exergoeconomic aspects. By the results, they have determined that the most necessary cost to reduce the cost is in the heat recovery unit. Kwak et al. [16] have performed thermoeconomic analysis of a ground-source heat pump system with a vertical or horizontal ground heat exchanger. Modified Productive Structure Analysis (MOPSA) method is used for thermoeconomic analysis. They have reported that the unit cost of heat delivered is $0.063 \$ / \mathrm{kWh}$, while the unit cost of electricity supplied to the system is 0.14 $\$ / \mathrm{kWh}$ and the coefficient of performance of the system is 3.27.

In this study, thermoeconomic analysis of a water-to-water heat pump system is performed on under different condenser and evaporator conditions. Same inlet temperatures of water supplied to condenser and evaporator are used in the experiments, which are $\mathrm{T}_{\text {in }}=14.4^{\circ} \mathrm{C}, 17{ }^{\circ} \mathrm{C}$ and $19^{\circ} \mathrm{C}$. Moreover, different volumetric flow rates are used for the water stream supplied to the condenser ( $\dot{\forall}=50 \mathrm{lt} / \mathrm{h}, 100 \mathrm{lt} / \mathrm{h}$ and $150 \mathrm{lt} / \mathrm{h}$ ), while volumetric flow rates of water stream supplied to evaporator are to be fixed as $\dot{\forall}=100 \mathrm{lt} / \mathrm{h}$ in all experiments. Modified Productive Structure Analysis (MOPSA) is used for thermoeconomic analysis of the heat pump system considered in this study. The unit costs of mechanical exergy, thermal exergy, heat delivered and negentropy are presented and the effects of condenser and evaporator conditions on the unit cost of these terms are discussed.

\section{SYSTEM DESCRIPTION AND EXPERIMENTAL SETUP}

A schematic diagram of experimental setup for the water-to-water heat pump considered in this study is shown in Figure 1. 


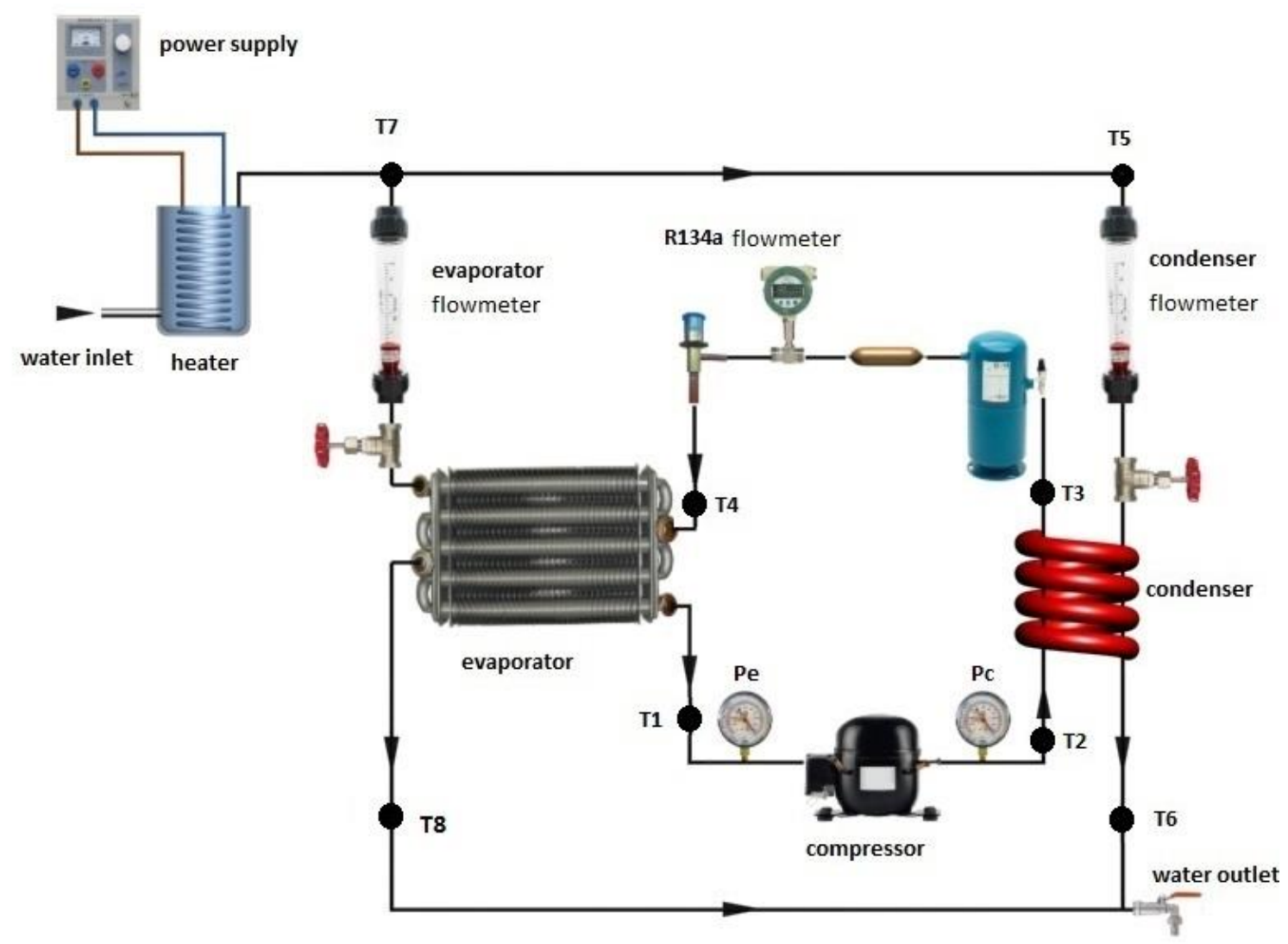

Figure 1. Experimental setup for heat pump system considered in this study

The system consists of four main components: compressor, condenser, expansion valve and evaporator. Refrigerant R-134a is used as working fluid for this study. R-134a enters to compressor as saturated vapor and is pressurized in compressor. R-134a leaving from compressor as superheated and pressurized enters to condenser. The refrigeration delivers heat to water supplied to condenser and leaves from condenser as saturated liquid. The pressure of refrigerant leaving from condenser is reduced in expansion valve to obtain a phase change for low temperatures in evaporator. Heat removed from medium is transferred to refrigerant in evaporator and refrigerant leaves from evaporator as saturated vapor.

An experimental setup is installed and experiments are realized for different inlet temperatures of water supplied to condenser and evaporator and different volumetric flow rates of water supplied to condenser. The volumetric flow rate of $100 \mathrm{lt} / \mathrm{h}$ is used for water supplied to evaporator in all experiments for each cases. The inlet temperatures for water supplied to condenser and evaporator are $14.4{ }^{\circ} \mathrm{C}, 17^{\circ} \mathrm{C}$ and $19^{\circ} \mathrm{C}$. An electrical heater controlled with a thermostat is used to provide the demanded temperatures for water supplied to condenser and evaporator. In temperature measurements for water supplied to condenser and evaporator and for refrigerant circulated in the system, multichannel data logger with PT100 type sensors is used. In pressure measurements for the system states, REFCO MR-205-DS-R22 is used for low pressure line, while REFCO MR305-DS-R22 is used for high pressure line. The experiments are also realized for different volumetric flow rate of water supplied to the condenser, while constant volumetric flow rate of $100 \mathrm{lt} / \mathrm{h}$ is used for the water supplied to the evaporator. The volumetric flow rates used for the water supplied to the condenser are $50 \mathrm{lt} / \mathrm{h}, 100 \mathrm{lt} / \mathrm{h}$ and $150 \mathrm{lt} / \mathrm{h}$. A turbine type flow meter is used for measurements of volumetric flow rate of refrigerant circulated in the system. In the measurement of volumetric flow rates of volumetric flow rate of water supplied to the condenser and evaporator, a rotameter type having measurement range of 40-400 lt/h is used.

The experiments are realized for 9 different cases by changing the inlet temperature of the water supplied to the condenser and evaporator and by changing the volumetric flow rate of water supplied to the condenser. The properties considered for each cases are presented in Table 1. 
Table 1. The cases considered for experiments of heat pump system

\begin{tabular}{|c|c|c|c|c|}
\hline Cases & $\begin{array}{c}\text { Inlet } \\
\text { temperature } \\
\text { for } \\
\text { condenser, } \\
\mathbf{T}_{\text {in }}\left({ }^{\mathbf{o}} \mathbf{C}\right)\end{array}$ & $\begin{array}{c}\text { Inlet } \\
\text { temperature } \\
\text { for } \\
\text { evaporator, } \\
\mathbf{T}_{\text {in }}\left({ }^{\mathbf{}} \mathbf{C}\right)\end{array}$ & $\begin{array}{c}\text { Volumetric } \\
\text { flow rate for } \\
\text { evaporator, } \\
\dot{\forall}(\mathbf{l t} / \mathbf{h})\end{array}$ & $\begin{array}{c}\text { Volumetric } \\
\text { flow rate for } \\
\text { condenser, } \\
\dot{\forall}(\mathbf{l t} / \mathbf{h})\end{array}$ \\
\hline Case I & 14.4 & 14.4 & 100 & 50 \\
\hline Case II & 14.4 & 14.4 & 100 & 100 \\
\hline Case III & 14.4 & 14.4 & 100 & 150 \\
\hline Case IV & 17 & 17 & 100 & 50 \\
\hline Case V & 17 & 17 & 100 & 100 \\
\hline Case VI & 17 & 17 & 100 & 150 \\
\hline Case VII & 19 & 19 & 100 & 50 \\
\hline Case VIII & 19 & 19 & 100 & 100 \\
\hline Case IX & 19 & 19 & 100 & 150 \\
\hline & & & & \\
\hline
\end{tabular}

The results obtained from experiments are presented for only Case I and Case IX. Table 2 and 3 show the properties obtained by experiments for each state located in the heat pump system shown in Figure 1 for Case I and Case IX, respectively.

Table 2. The properties for each state located in the heat pump system for Case I

\begin{tabular}{|c|c|c|c|c|c|c|}
\hline State & $\dot{\boldsymbol{m}}(\mathbf{k g} / \mathbf{s})$ & $\mathbf{T}\left({ }^{\circ} \mathbf{C}\right)$ & $\mathbf{P}(\mathbf{b a r})$ & $\mathbf{h}(\mathbf{k J} / \mathbf{k g})$ & $\mathbf{s}(\mathbf{k J} / \mathbf{k g K})$ & $\mathbf{e x}(\mathbf{k J} / \mathbf{k g})$ \\
\hline 1 & 0.006406 & 1.6 & 3.1 & 399.41 & 1.7258 & 27.278200 \\
\hline 2 & 0.006406 & 68.96 & 15 & 441.96 & 1.7548 & 61.186200 \\
\hline 3 & 0.006406 & 55.23 & 15 & 279.68 & 1.2616 & 45.879800 \\
\hline 4 & 0.006406 & 1.6 & 3.1 & 279.68 & 1.29 & 37.416600 \\
\hline 5 & 0.013889 & 14.4 & 4 & 60.85 & 0.21567 & 1.085940 \\
\hline 6 & 0.013889 & 28.32 & 4 & 119.07 & 0.41341 & 0.379420 \\
\hline 7 & 0.027778 & 14.4 & 4 & 60.85 & 0.21567 & 1.085940 \\
\hline 8 & 0.027778 & 9.78 & 4 & 41.487 & 0.14779 & 1.951180 \\
\hline
\end{tabular}

Table 3. The properties for each state located in the heat pump system for Case IX

\begin{tabular}{|c|c|c|c|c|c|c|}
\hline State & $\boldsymbol{m}(\mathbf{k g} / \mathbf{s})$ & $\mathbf{T}\left({ }^{\circ} \mathbf{C}\right)$ & $\mathbf{P}(\mathbf{b a r})$ & $\mathbf{h}(\mathbf{k J} / \mathbf{k g})$ & $\mathbf{s}(\mathbf{k J} / \mathbf{k g K})$ & $\mathbf{e x}(\mathbf{k J} / \mathbf{k g})$ \\
\hline 1 & 0.007968 & 7.6 & 3.82 & 402.84 & 1.7228 & 31.6022 \\
\hline 2 & 0.007968 & 73.36 & 19.33 & 443.02 & 1.7495 & 63.8256 \\
\hline 3 & 0.007968 & 60.8 & 19.33 & 288.63 & 1.2884 & 46.8434 \\
\hline 4 & 0.007968 & 7.6 & 3.82 & 288.63 & 1.3158 & 38.6782 \\
\hline 5 & 0.041667 & 19 & 4 & 80.105 & 0.28211 & 0.54182 \\
\hline 6 & 0.041667 & 25.33 & 4 & 106.58 & 0.37175 & 0.3041 \\
\hline 7 & 0.027778 & 19 & 4 & 80.105 & 0.28211 & 0.54182 \\
\hline 8 & 0.027778 & 12.26 & 4 & 51.885 & 0.18438 & 1.44536 \\
\hline
\end{tabular}

\section{THERMOECONOMIC ANALYSIS}

Thermoeconomic analysis provides the detailed information about unit cost of any thermodynamical parameter, especially for product of thermal systems, to designer or engineer and enables cost allocation when system analyzed has two or more products. There are several thermoeconomic methods in the literature [17-28]. Among these methods, Modified Productive Structure Analysis (MOPSA) method was selected for this study because of that MOPSA method assigns a unit cost for entropy production and provides correct results for unit cost of products for thermal systems [29].

\section{Modified Productive Structure Analysis (MOPSA)}

MOPSA method, which was firstly introduced by Kim et al. [23], provides exergy costing without any flow stream cost calculation. In MOPSA method, the component of thermomechanical exergy can be costed in 
separate form as thermal and mechanical exergy costs. Therefore, general exergy balance equation can be written for MOPSA application as follows:

$$
\begin{gathered}
\dot{E}_{x}^{C H E}+\left(\sum_{\text {inlet }} \dot{E}_{x}^{T}-\sum_{\text {outlet }} \dot{E}_{x}^{T}\right)+\left(\sum_{\text {inlet }} \dot{E}_{x}^{P}-\sum_{\text {outlet }} \dot{E}_{x}^{P}\right) \\
+T_{o}\left(\sum_{\text {inlet }} \dot{S}_{i}-\sum_{\text {outlet }} \dot{S}_{i}\right)=\dot{E}_{x}^{W}
\end{gathered}
$$

In Equation 1, first term on the left side express the chemical exergy of fuel supplied to the system. Second and third terms on the left side are thermal and mechanical components of thermomechanical exergy of any stream, respectively. Fourth term on the left side denote exergy destruction of the component considered. The term on the right side of Equation 1 the exergy value of work, which is equal to the value of work.

Thermoeconomics is an engineering branch that combines thermodynamics and economics analysis. Therefore, economic analysis should be applied to realize the thermoeconomical analysis of a thermal system. In this study, the annualized (levelized) cost method proposed by Moran [30] is used to estimate the capital cost of components. The present worth factor (PWF) and the capital recovery factor (CRF) are given as follows, respectively:

$$
\begin{gathered}
P W F=\frac{1}{(1+i)^{n}} \\
C R F=\frac{i(1+i)^{n}}{(1+i)^{n}-1}
\end{gathered}
$$

where $i$ and $n$ terms denote the interest rate and the life time of system, respectively. The salvage value of the system can be calculated as follows:

$$
S V=\mu T C I
$$

where $\mu$ and TCI represent the salvage value ratio and the total capital investment of the system. The present worth $(\mathrm{PW})$ and the annual capital cost of the system $(A \dot{C})$ are given as follows, respectively.

$$
\begin{aligned}
& P W=T C I-S V \times P W F \\
& A \dot{C}=P W \times C R F
\end{aligned}
$$

The capital investment cost of overall system is calculated as follows:

$$
\dot{Z}_{\text {system }}=\phi \frac{A \dot{C}}{\tau}
$$

where $\phi$ and $\tau$ denote the maintenance factor and the total annual number of operating hours of the system at full load capacity. The capital investment cost rate of kth component of the system can be calculated as follows:

$$
\dot{Z}_{k}=\dot{Z}_{\text {system }} \frac{P E C_{k}}{T C I}
$$

where PEC express the purchased equipment cost of kth component in the system.

The general cost balance equation for MOPSA based adding unit cost of related terms in the exergy balance equation given in Equation 9 can be written as follows: 


$$
\begin{aligned}
E \dot{x}^{C H E} C_{0}+ & \left(\sum_{\text {inlet }} E \dot{x}_{\text {in }}^{T}-\sum_{\text {outlet }} E \dot{x}_{\text {out }}^{T}\right) C_{T}+\left(\sum_{\text {inlet }} E \dot{x}_{\text {in }}^{P}-\sum_{\text {outlet }} E \dot{x}_{\text {out }}^{P}\right) C_{P} \\
& +T_{0}\left(\sum_{\text {inlet }} \dot{S}_{\text {in }}-\sum_{\text {outlet }} \dot{S}_{\text {out }}\right) C_{S}+\dot{Z}_{k}=E \dot{x}^{W} C_{W}
\end{aligned}
$$

where $T$ and $P$ superscripts represent thermal and mechanical components of thermomechanical exergy, respectively. $C_{0}, C_{S}$ and $C_{W}$ are the unit exergy cost of fuel, entropy and work, respectively. $C_{T}$ and $C_{P}$ are also the unit exergy cost of thermal and mechanical components of thermomechanical exergy, respectively.

\section{MOPSA Application for Water-to-Water Heat Pump}

The exergy balance equations are obtained by applying the general exergy balance equation given in Equation 1 to each components of the heat pump system shown in Figure 1. The obtained equations are given as follows:

Compressor:

$$
\left(E \dot{x}_{1}^{T}-E \dot{x}_{2}^{T}\right)+\left(E \dot{x}_{1}^{P}-E \dot{x}_{2}^{P}\right)+T_{0}\left(\dot{S}_{1}-\dot{S}_{2}\right)=E \dot{x}^{W}
$$

Condenser:

$$
\begin{gathered}
\left(E \dot{x}_{2}^{T}-E \dot{x}_{3}^{T}+E \dot{x}_{5}^{T}-E \dot{x}_{6}^{T}\right)+\left(E \dot{x}_{2}^{P}-E \dot{x}_{3}^{P}+E \dot{x}_{5}^{P}-E \dot{x}_{6}^{P}\right) \\
+T_{0}\left(\dot{S}_{2}-\dot{S}_{3}+\dot{S}_{5}-\dot{S}_{6}\right)=0
\end{gathered}
$$

Expansion valve:

$$
\left(E \dot{x}_{3}^{T}-E \dot{x}_{4}^{T}\right)+\left(E \dot{x}_{3}^{P}-E \dot{x}_{4}^{P}\right)+T_{0}\left(\dot{S}_{3}-\dot{S}_{4}\right)=0
$$

Evaporator:

$$
\begin{gathered}
\left(E \dot{x}_{4}^{T}-E \dot{x}_{1}^{T}+E \dot{x}_{7}^{T}-E \dot{x}_{8}^{T}\right) C_{T}+\left(E \dot{x}_{4}^{P}-E \dot{x}_{1}^{P}+E \dot{x}_{7}^{P}-E \dot{x}_{8}^{P}\right) \\
+T_{0}\left(\dot{S}_{4}-\dot{S}_{1}+\dot{S}_{7}-\dot{S}_{8}\right)=0
\end{gathered}
$$

In this study, for economic analysis, the interest ratio $(i)$ and the life time of the system $(n)$ are assumed to be $10 \%$ and 5 years, respectively. In addition; the salvage value ratio $(\mu)$, the maintenance factor $(\phi)$ and the total annual number of operating hours of the system at full load capacity () are selected to be $12 \%, 1.06$ and 2880 hours, respectively.

The cost balance equations are obtained by applying the general cost balance equation given in Equation 9 to each components of the heat pump system illustrated in Figure 1 and are given as follows:

Compressor:

$$
\left(E \dot{x}_{1}^{T}-E \dot{x}_{2}^{T}\right) C_{T}+\left(E \dot{x}_{1}^{P}-E \dot{x}_{2}^{P}\right) C_{P}+\left[T_{0}\left(\dot{S}_{1}-\dot{S}_{2}\right)\right] C_{S}+\dot{Z}_{c o m}=E \dot{x}^{W} C_{W}
$$

Condenser:

$$
\left(E \dot{x}_{2}^{T}-E \dot{x}_{3}^{T}\right) C_{T}+\left(E \dot{x}_{2}^{P}-E \dot{x}_{3}^{P}\right) C_{P}-\dot{Q}_{r o o m} C_{H}+\left[T_{0}\left(\dot{S}_{2}-\dot{S}_{3}\right)\right] C_{S}+\dot{Z}_{c n d}=0
$$

Expansion valve:

$$
\left(E \dot{x}_{3}^{T}-E \dot{x}_{4}^{T}\right) C_{T}+\left(E \dot{x}_{3}^{P}-E \dot{x}_{4}^{P}\right) C_{P}+\left[T_{0}\left(\dot{S}_{3}-\dot{S}_{4}\right)\right] C_{S}+\dot{Z}_{\text {exp }}=0
$$


Evaporator:

$$
\left(E \dot{x}_{4}^{T}-E \dot{x}_{1}^{T}\right) C_{T}+\left(E \dot{x}_{4}^{P}-E \dot{x}_{1}^{P}\right) C_{P}+\left(E \dot{x}_{7}-E \dot{x}_{8}\right) .0+\left[T_{0}\left(\dot{S}_{4}-\dot{S}_{1}\right)\right] C_{S}+\dot{Z}_{e v a}=0
$$

where $\dot{Q}_{\text {room }}$ term represents the heat transfer rate delivered to medium heated and it is formulated as follows:

$$
\dot{Q}_{\text {room }}=\left(E \dot{x}_{6}^{T}-E \dot{x}_{5}^{T}\right)+\left(E \dot{x}_{6}^{P}-E \dot{x}_{5}^{P}\right)+T_{0}\left(\dot{S}_{6}-\dot{S}_{5}\right)
$$

With writing from Equation 14 to Equation 17, all cost balance equations required to calculate the unknown unit cost parameters assigned as $C_{T}, C_{P}, C_{S}$ and $C_{H}$ are obtained. The value of the unit cost of electricity supplied to the system $\left(C_{W}\right)$ is $0.0586 \$ / \mathrm{kWh}[31]$. The unit cost of heat gained by evaporator is assumed to be 0 , similarly with Reference [16].

The overall cost balance equation is obtained by summing Equation 14 to Equation 17 as follows:

$$
-\dot{Q}_{\text {room }} C_{H}+\sum \dot{Z}_{k}=E \dot{x}^{W} C_{W}
$$

The unit cost of heat obtained by solving Equation 14 to Equation 17 should be same with the result obtained by Equation 19.

\section{RESULTS AND DISCUSSION}

The effect of volumetric flow rate and inlet temperature of condenser cooling water on the unit cost of heat delivered to medium by a water-to-water heat pump system is investigated. Three different volumetric volume rates $(\dot{\forall}=50 \mathrm{lt} / \mathrm{h}, 100 \mathrm{lt} / \mathrm{h}$ and $150 \mathrm{lt} / \mathrm{h})$ and three different inlet temperatures $\left(T_{i n}=14^{\circ} \mathrm{C}, 17^{\circ} \mathrm{C}\right.$ and 19 ${ }^{\circ} \mathrm{C}$ ) of condenser cooling water are considered. For evaporator, same inlet temperatures are used with that of condenser for each case. However, constant volumetric flow rate of $100 \mathrm{lt} / \mathrm{h}$ are used for each case. By this way, the exergy and thermoeconomic analyses are applied for 9 different cases of the heat pump system. However, the results obtained for only Case I and Case IX are presented in this paper.

Coefficient of performance (COP) and second law efficiency $\left(\eta_{I I}\right)$ values of the water-to-water heat pump system for each cases are given in Table 4.

Table 4. COP and $\eta_{I I}$ values of water-to-water heat pump system for each case

\begin{tabular}{|c|c|c|c|c|c|c|c|c|c|}
\hline & Case I & Case II & Case III & Case IV & Case V & Case VI & Case VII & Case VIII & $\begin{array}{c}\text { Case } \\
\text { IX }\end{array}$ \\
\hline COP & 2.98 & 3.21 & 3.45 & 2.94 & 3.19 & 3.46 & 2.90 & 3.13 & 3.44 \\
\hline$\eta_{I I}$ & 0.137 & 0.080 & 0.061 & 0.151 & 0.089 & 0.069 & 0.164 & 0.096 & 0.073 \\
\hline
\end{tabular}

It is found that COP value of the system increases with increase in volumetric flow rate of inlet water supplied to condenser, while it is not almost affected by inlet temperature of water supplied to condenser and evaporator. However, the second law efficiency of the system decreases with increasing volumetric flow rate of inlet water supplied to condenser. In addition, increase in inlet temperature of water supplied to condenser and evaporator causes to increase in the second law efficiency of the system. The highest second law efficiency value of the system is obtained to be $16.4 \%$ for $\dot{\forall}=50 \mathrm{lt} / \mathrm{h}$ and $\mathrm{T}=19^{\circ} \mathrm{C}$, while the lowest one is obtained to be $6.1 \%$ for $\dot{\forall}=150 \mathrm{lt} / \mathrm{h}$ and $\mathrm{T}=14.4{ }^{\circ} \mathrm{C}$.

Exergy balance values obtained for each component with applying Equations 10 to Equation 13 to related components by using the data presented in Table 2 and 3 for Case I and Case IX are illustrated in Table 5 and Table 6, respectively. 
Table 5. Exergy balance for the system components of the heat pump system for Case I

\begin{tabular}{|c|c|c|c|c|c|}
\hline Component & $\begin{array}{c}\text { Refrigerant } \\
(\mathbf{k W})\end{array}$ & $\begin{array}{c}\text { Water stream } \\
(\mathbf{k W})\end{array}$ & $\begin{array}{c}\text { Heat flow } \\
(\mathbf{k W})\end{array}$ & $\begin{array}{c}\text { Lost work rate } \\
(\mathbf{k W})\end{array}$ & $\begin{array}{c}\text { Work input rate } \\
(\mathbf{k W})\end{array}$ \\
\hline Compressor & 0.217215 & & & 0.055361 & -0.27205 \\
\hline Condenser & -0.098053 & & 0.808618 & -0.941513 & \\
\hline Exp. valve & -0.054215 & & & 0.054215 & \\
\hline Evaporator & -0.064947 & -0.026689 & & 0.831937 & \\
\hline Total & 0.0 & -0.026689 & 0.808618 & 0.0 & -0.27205 \\
\hline
\end{tabular}

Table 6. Exergy balance for the system components of the heat pump system for Case IX

\begin{tabular}{|c|c|c|c|c|c|}
\hline Component & $\begin{array}{c}\text { Refrigerant } \\
(\mathbf{k W})\end{array}$ & $\begin{array}{c}\text { Water } \\
\text { stream } \mathbf{( k W )}\end{array}$ & $\begin{array}{c}\text { Heat flow } \\
(\mathbf{k W})\end{array}$ & $\begin{array}{c}\text { Lost work rate } \\
(\mathbf{k W})\end{array}$ & $\begin{array}{c}\text { Work input rate } \\
(\mathbf{k W})\end{array}$ \\
\hline Compressor & 0.256756 & & & -0.0634 & -0.32136 \\
\hline Condenser & -0.135314 & & 1.10313 & 1.09487 & \\
\hline Exp. valve & -0.065060 & & & -0.06506 & \\
\hline Evaporator & -0.056382 & -0.025099 & & -0.96641 & -0.32136 \\
\hline Total & 0.0 & -0.025099 & 1.10313 & 0.0 & \\
\hline
\end{tabular}

The negative sign for exergies given in Table 5 and 6 expresses the fuel concept of the component, while the positive sign expresses the product concept of the component. As can be seen from Table 5 and 6 , the maximum exergy destruction is observed in condenser. The sign of lost work rate of condenser is positive, differently with other components. It is due to that condenser is boundary of the system, and negative sign is added for boundary terms in MOPSA method.

The capital investment costs for the system components obtained with economic analysis are presented in Table 7.

Table 7. The purchased equipment cost and capital investment cost values for the system components

\begin{tabular}{|c|c|c|}
\hline Component & PEC (\$) & $\dot{Z} \mathbf{( \$ / h )}$ \\
\hline Compressor & 94.41 & 0.00847 \\
\hline Condenser & 54.28 & 0.00487 \\
\hline Expansion valve & 11.8 & 0.00105 \\
\hline Evaporator & 102.55 & 0.00921 \\
\hline Total & 263.04 & 0.02360 \\
\hline
\end{tabular}

The purchased equipment cost of overall system is $263.04 \$$. The capital investment cost of overall system is calculated to be $0.02360 \$ / \mathrm{h}$.

The cost balance equations given by Equation 14 to Equation 17 should be solved with using the data presented in Table 2 and 5 and Table 3 and 6 for Case I and Case IX, respectively. By this way, the unit cost of unknown parameters can be found.

The results obtained for the unit cost of thermal exergy are presented in Table 8 for all cases given in Table 1.

Table 8. The change of unit cost of thermal exergy $C_{T}(\$ / \mathrm{kWh})$ with temperature and volumetric flow rate of water supplied to the condenser

\begin{tabular}{|c|c|c|c|}
\hline & $\dot{\forall}=\mathbf{5 0} \mathbf{~ l t} / \mathbf{h}$ & $\dot{\forall}=\mathbf{1 0 0} \mathbf{~ l t} / \mathbf{h}$ & $\dot{\forall}=\mathbf{1 5 0} \mathbf{~ l t} / \mathbf{h}$ \\
\hline $\mathbf{T}=\mathbf{1 4}{ }^{\circ} \mathrm{C}$ & 0.1413 & 0.1416 & 0.1424 \\
\hline $\mathbf{T}=17^{\circ} \mathrm{C}$ & 0.1374 & 0.1372 & 0.1379 \\
\hline $\mathbf{T}=19{ }^{\circ} \mathrm{C}$ & 0.1347 & 0.1349 & 0.1362 \\
\hline
\end{tabular}


As can be seen from Table 8, the unit cost of thermal exergy decreases with increase in inlet temperature of the water supplied to the condenser and evaporator. In addition, it is found that increase in mass flow rate of water supplied to the condenser causes to an increase in the unit cost of thermal exergy.

Table 9 shows the obtained results for the unit cost of mechanical exergy for different volumetric flow rates of water supplied to the condenser and for different inlet temperatures of water supplied to the condenser and evaporator.

Table 9. The change of unit cost of mechanical exergy $C_{P}(\$ / \mathrm{kWh})$ with temperature and volumetric flow rate of water supplied to the condenser

\begin{tabular}{|c|c|c|c|}
\hline & $\dot{\forall}=\mathbf{5 0} \mathbf{~ l t} / \mathbf{h}$ & $\dot{\forall}=\mathbf{1 0 0} \mathbf{~ l t} / \mathbf{h}$ & $\dot{\forall}=\mathbf{1 5 0} \mathbf{~ l t} / \mathbf{h}$ \\
\hline $\mathbf{T}=\mathbf{1 4}{ }^{\circ} C$ & 0.0734 & 0.0732 & 0.0733 \\
\hline $\mathbf{T}=17^{\circ} C$ & -0.0276 & 0.0627 & 0.0576 \\
\hline $\mathbf{T}=19{ }^{\circ} C$ & 0.0518 & 0.0498 & 0.0509 \\
\hline
\end{tabular}

As can be seen from Table 9, it may be said that the unit cost of mechanical exergy has a decreasing trend with increasing inlet temperature of water supplied to the condenser and evaporator. Moreover, it may be said that the obtained values for unit cost of mechanical exergy for $\dot{\forall}=100 \mathrm{lt} / \mathrm{h}$ are lower compared to that of other volumetric flow rates.

The variation of unit cost of negentropy with the inlet temperature of water supplied to the condenser and evaporator and the volumetric flow rate of water supplied to the condenser is given in Table 10.

Table 10. The change of unit cost of negentropy $C_{S}(\$ / \mathrm{kWh})$ with temperature and volumetric flow rate of water supplied to the condenser

\begin{tabular}{|c|c|c|c|}
\hline & $\dot{\forall}=\mathbf{5 0} \mathbf{~ l t} / \mathbf{h}$ & $\dot{\forall}=\mathbf{1 0 0} \mathbf{~ l t} / \mathbf{h}$ & $\dot{\forall}=\mathbf{1 5 0} \mathbf{~ t t} / \mathbf{h}$ \\
\hline $\mathbf{T}=\mathbf{1 4}{ }^{\circ} C$ & 0.0221 & 0.0207 & 0.0195 \\
\hline $\mathbf{T}=17^{\circ} C$ & 0.0211 & 0.0196 & 0.0178 \\
\hline $\mathbf{T}=19{ }^{\circ} C$ & 0.0203 & 0.0186 & 0.0175 \\
\hline
\end{tabular}

It is found that the unit cost of negentropy decreases with increase in the inlet temperature of water supplied to the system and with increase in the volumetric flow rate of water supplied to the condenser. The minimum unit cost of negentropy is obtained to be $0.0175 \$ / \mathrm{kWh}$ for $\dot{\forall}=150 \mathrm{lt} / \mathrm{h}$ and $\mathrm{T}=19^{\circ} \mathrm{C}$.

The results obtained for the unit cost of heat delivered are presented in Table 11 for all cases given in Table 1.

Table 11. The change of unit cost of heat delivered $C_{H}(\$ / \mathrm{kWh})$ with temperature and volumetric flow rate of water supplied to the condenser

\begin{tabular}{|c|c|c|c|}
\hline & $\dot{\forall}=\mathbf{5 0} \mathbf{~ l t} / \mathbf{h}$ & $\dot{\forall}=\mathbf{1 0 0} \mathbf{~ l t} / \mathbf{h}$ & $\dot{\forall}=\mathbf{1 5 0} \mathbf{~ l t} / \mathbf{h}$ \\
\hline $\mathbf{T}=\mathbf{1 4}{ }^{\circ} C$ & 0.0489 & 0.0460 & 0.0433 \\
\hline $\mathbf{T}=17^{\circ} C$ & 0.0459 & 0.0429 & 0.0401 \\
\hline $\mathbf{T}=19{ }^{\circ} C$ & 0.0434 & 0.0406 & 0.0385 \\
\hline
\end{tabular}

It is found that the unit cost of heat delivered decreases with increase in the inlet temperature of water supplied to the condenser and evaporator and with increase in the volumetric flow rate of water supplied to the condenser. The lowest unit cost of heat delivered is obtained to be $0.0385 \$ / \mathrm{kWh}$ for Case IX, while the highest one is obtained to be $0.0489 \$ / \mathrm{kWh}$ for Case I.

The cost flow rates of the system components for Case I and Case IX are presented in Table 12 and 13, respectively.

For Case I, the cost flow rate of heat delivered for the condenser is found to be $-0.039195 \$ / \mathrm{kWh}$, while the cost flow rate of electricity supplied to the system is $0.015581 \$ / \mathrm{kWh}$. Whereas, for Case IX, the cost flow rate of heat delivered for the condenser is found to be $-0.42471 \$ / \mathrm{kWh}$, while the cost flow rate of electricity 
supplied to the system is $0.018831 \$ / \mathrm{kWh}$. The highest values of cost flow rate for negentropy are obtained for the condenser.

Table 12. The cost flow rates of the system components for Case I

\begin{tabular}{|c|c|c|c|c|c|c|}
\hline Component & $C_{T}(\mathbf{\$} / \mathbf{h})$ & $C_{P} \mathbf{( \$ / \mathbf { h } )}$ & $C_{H} \mathbf{( \$ / \mathbf { h } )}$ & $C_{S} \mathbf{( \$ / \mathbf { h } )}$ & $C_{W}(\mathbf{\$} / \mathbf{h})$ & $\dot{Z}(\mathbf{\$} / \mathbf{h})$ \\
\hline Compressor & -0.015240 & -0.007690 & 0.000000 & -0.001112 & 0.015581 & 0.008470 \\
\hline Condenser & 0.013955 & 0.000000 & -0.039195 & 0.020326 & 0.000000 & 0.004870 \\
\hline Expansion valve & -0.007689 & 0.007690 & 0.000000 & -0.001051 & 0.000000 & 0.001050 \\
\hline Evaporator & 0.008975 & 0.000000 & 0.000000 & -0.018163 & 0.000000 & 0.009210 \\
\hline TOTAL & 0.000000 & 0.000000 & -0.039195 & 0.000000 & 0.015581 & 0.023600 \\
\hline
\end{tabular}

Table 13. The cost flow rates of the system components for Case IX

\begin{tabular}{|c|c|c|c|c|c|c|}
\hline Component & $C_{T} \mathbf{( \$ / h )}$ & $C_{P} \mathbf{( \$ / h )}$ & $C_{H} \mathbf{( \$ / h )}$ & $C_{S} \mathbf{( \$ / \mathbf { h } )}$ & $C_{W}(\$ / \mathbf{h})$ & $\dot{Z} \mathbf{( \$ / h )}$ \\
\hline Compressor & -0.020953 & -0.005238 & 0.000000 & -0.001110 & 0.018831 & 0.008470 \\
\hline Condenser & 0.018429 & 0.000000 & -0.042471 & 0.019160 & 0.000000 & 0.004870 \\
\hline Expansion valve & -0.005155 & 0.005238 & 0.000000 & -0.001139 & 0.000000 & 0.001050 \\
\hline Evaporator & 0.007679 & 0.000000 & 0.000000 & -0.016912 & 0.000000 & 0.009210 \\
\hline TOTAL & 0.000000 & 0.000000 & -0.042471 & 0.000000 & 0.018831 & 0.023600 \\
\hline
\end{tabular}

\section{CONCLUDING REMARKS}

Thermoeconomic analysis of a water-to-water heat pump is realized for different evaporator and condenser conditions. Different inlet temperature of $\mathrm{T}_{\text {in }}=14.4^{\circ} \mathrm{C}, 17^{\circ} \mathrm{C}$ and $19^{\circ} \mathrm{C}$ are used for water supplied to the condenser and evaporator and different volumetric flow rates of $\dot{\forall}=50 \mathrm{lt} / \mathrm{h}, 100 \mathrm{lt} / \mathrm{h}$ and $150 \mathrm{lt} / \mathrm{h}$ are used for water supplied to the condenser. Constant volumetric flow rate of $\dot{\forall}=100 \mathrm{lt} / \mathrm{h}$ for water supplied to the evaporator is used. Modified Productive Structure Analysis (MOPSA) method is used for thermoeconomic analysis. Results showed that unit costs of heat delivered and of negentropy increases with increase in the volumetric flow rate of water supplied to the condenser and with increase in the inlet temperature of water supplied to the condenser. By this way, the unit costs of heat delivered and of negentropy for Case IX are lower than that of Case I. However, the result obtained for cost flow rates of heat delivered for Case IX is higher than that of Case I. It is due to that the electricity consumption increases with increasing volumetric flow rate of water supplied to the condenser and the amount of heat delivered. Moreover, it is found that the unit cost of negentropy decreases with increase in the inlet temperature of water supplied to the condenser and with increase in the volumetric flow rate of water supplied to the condenser and evaporator.

\section{AKNOWLEGMENT}

This work was supported by Scientific Research Projects Coordination Unit of Karabuk University. Project Number: KBU-BAP-14/1-DR-001

\section{NOMENCLATURE}

$A \dot{C} \quad$ annual capital cost [\$/year]

$C$ unit cost [\$/kWh]

ex specific exergy $[\mathrm{kJ} / \mathrm{kg}]$

$\dot{E}_{x} \quad$ exergy rate $[\mathrm{kW}]$

$h$ specific enthalpy $[\mathrm{kJ} / \mathrm{kg}]$

$i \quad$ interest rate [\%]

$\dot{m} \quad$ mass flow rate $[\mathrm{kg} / \mathrm{s}]$

$n \quad$ life time of system [year]

$P \quad$ pressure [bar] 


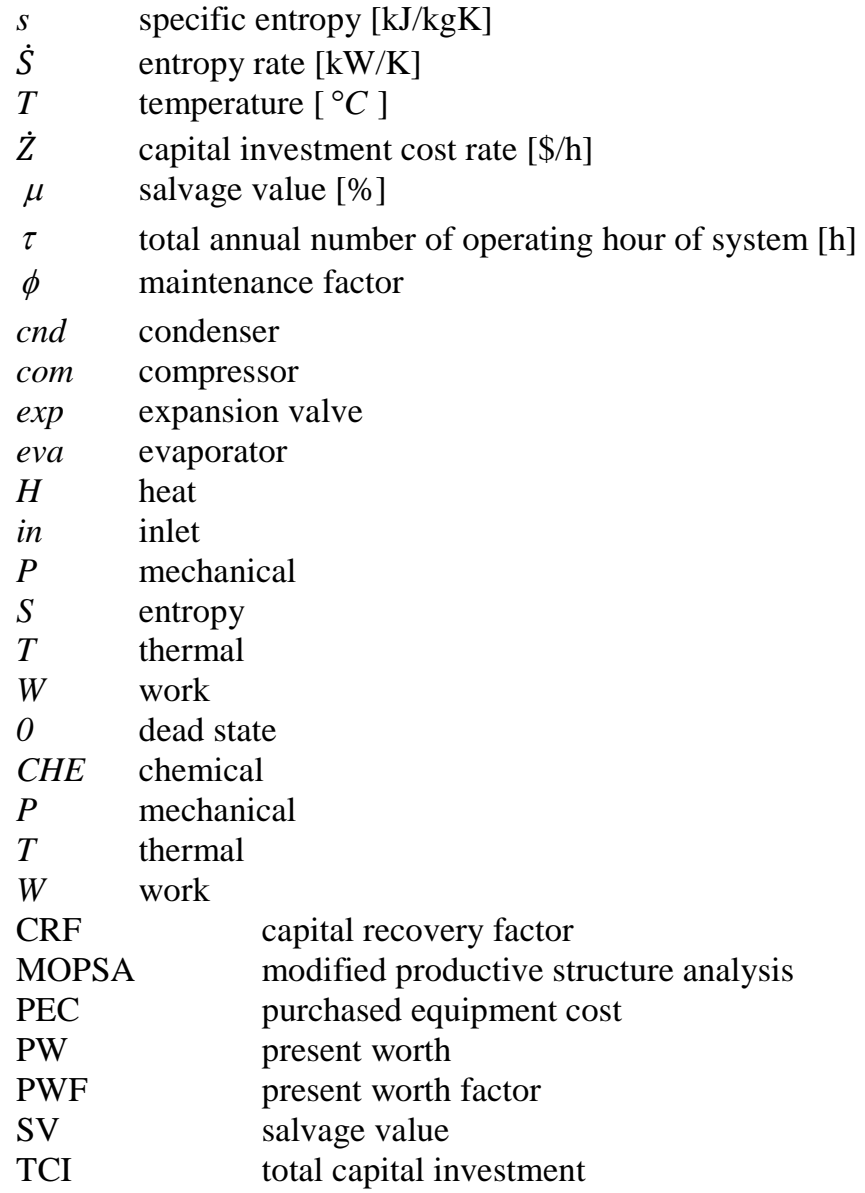

\section{REFERENCES}

[1] Waheed, M. A., Oni, A. O., Adejuyigbe, S. B., Adewumi, B. A., Fadare, D. A. (2014). Performance enhancement of vapor recompression heat pump. Applied energy, 114, 69-79.

[2] Qureshi, B. A., Zubair, S. M. (2013). Cost optimization of heat exchanger inventory for mechanical subcooling refrigeration cycles. International Journal of Refrigeration, 36(4), 1243-1253.

[3] Kodal, A., Sahin, B., Ekmekci, I., Yilmaz, T. (2003). Thermoeconomic optimization for irreversible absorption refrigerators and heat pumps. Energy Conversion and Management, 44(1), 109-123.

[4] Kodal, A., Sahin, B., Yilmaz, T. (2000). Effects of internal irreversibility and heat leakage on the finite time thermoeconomic performance of refrigerators and heat pumps. Energy Conversion and Management, 41(6), 607619.

[5] Teyber, R., Trevizoli, P. V., Christiaanse, T. V., Govindappa, P., Niknia, I., Rowe, A. (2017). Permanent magnet design for magnetic heat pumps using total cost minimization. Journal of Magnetism and Magnetic Materials, 442, 87-96.

[6] Esfahani, I. J., Yoo, C. (2014). A highly efficient combined multi-effect evaporation-absorption heat pump and vapor-compression refrigeration part 2: Thermoeconomic and flexibility analysis. Energy, 75, 327-337.

[7] Verda, V., Caccin, M., Kona, A. (2016). Thermoeconomic cost assessment in future district heating networks. Energy, 117, 485-491.

[8] Arat, H., Arslan, O. (2017). Exergoeconomic analysis of district heating system boosted by the geothermal heat pump. Energy, 119, 1159-1170.

[9] Erbay, Z., Hepbasli, A. (2017). Assessment of cost sources and improvement potentials of a ground-source heat pump food drying system through advanced exergoeconomic analysis method. Energy, 127, 502-515.

[10] Sayyadi, H., \& Nejatolahi, M. (2011). Thermodynamic and thermoeconomic optimization of a cooling tower-assisted ground source heat pump. Geothermics, 40(3), 221-232.

[11] Erbay, Z., Hepbasli, A. (2017). Exergoeconomic evaluation of a ground-source heat pump food dryer at varying dead state temperatures. Journal of cleaner production, 142, 1425-1435. 
[12] Mastrullo, R., Renno, C. (2010). A thermoeconomic model of a photovoltaic heat pump. Applied Thermal Engineering, 30(14-15), 1959-1966.

[13] Akbulut, U., Utlu, Z., Kincay, O. (2016). Exergoenvironmental and exergoeconomic analyses of a vertical type ground source heat pump integrated wall cooling system. Applied Thermal Engineering, 102, 904-921.

[14] Qin N., Hao P. Z. (2017). The operation characteristics of sewage source heat pump system and the analysis of its thermal economic benefits. Applied Thermal Engineering. 124, 1083-1089

[15] Erbay Z., Hepbaşlı A. (2017). Advanced exergoeconomic evaluation of a heat pump food dryer. Biosystems Engineering. 124, 29-39

[16] Kwak, H. Y., You, Y., Oh, S. D., Jang, H. N. (2014). Thermoeconomic analysis of ground- source heat pump systems. International Journal of Energy Research, 38(2), 259-269.

[17] von Spakovsky M. R., Evans R. B. (1993). Engineering functional analysis-part I. ASME J Energy Resour Technol. 155, 86-92.

[18] Rosen, M. A., Dincer, I. (2003). Exergy-cost-energy-mass analysis of thermal systems and processes. Energy Conversion and Management, 44(10), 1633-1651.

[19] Tsatsaronis G., Lin L., Pisa J. (1993). Exergy costing in exergoeconomics. ASME J Energy Resour Technol. 155, 9-16.

[20] Tsatsaronis, G., Moran, M. J. (1997). Exergy-aided cost minimization. Energy Conversion and Management, 38(15-17), 1535-1542.

[21] Tsatsaronis, G., Park, M. H. (2002). On avoidable and unavoidable exergy destructions and investment costs in thermal systems. Energy Conversion and Management, 43(9-12), 1259-1270.

[22] Tsatsaronis G., Lin L. (1990). On exergy costing in exergoeconomics. In: Tsatsaronis G, Bajura RA, Kenney WF, Reistad GM, editors. Computer-aided energy systems analysis. New York: ASME, 1-11.

[23] Kim, S. M., Oh, S. D., Kwon, Y. H., Kwak, H. Y. (1998). Exergoeconomic analysis of thermal systems. Energy, 23(5), 393-406.

[24] Lazzaretto A., Tsatsaronis G. (1997). On the quest for objective equations in exergy costing. In: Ramalingam ML, Lage JG, Mei VC, Chapman JN, editors. Proceedings of the ASME advanced energy systems division. New York: ASME, 413-428.

[25] Lazzaretto A., Tsatsaronis G. (1999). On the calculation of efficiencies and costs in thermal systems. In: Aceves SM, Garimella S, Peterson R, editors. Proceedings of the ASME advanced energy systems division. New York: ASME, 421-430.

[26] Erlach, B., Serra, L., Valero, A. (1999). Structural theory as standard for thermoeconomics. Energy Conversion and Management, 40(15-16), 1627-1649.

[27] Lozano, M. A., Valero, A. (1993). Theory of the exergetic cost. Energy, 18(9), 939-960.

[28] Frangopoulos, C. A. (1987). Thermo-economic functional analysis and optimization. Energy, 12(7), 563571.

[29] Uysal, C., Kurt, H., Kwak, H. Y. (2017). Exergetic and thermoeconomic analyses of a coal-fired power plant. International Journal of Thermal Sciences, 117, 106-120.

[30] Moran, M. J. (1982). Availability analysis: a guide to efficient energy use. Englewood Cliffs NJ, Prentice Hall,

[31] Enerjisa Başkent Electricity Retail Sales Co. 